\title{
Research on the Phenomenon of Obtaining Certificates among College Students
}

\author{
Lu Dan, Wang Qiu and Duan Jingyan \\ School of Finance and Public Management, Yunnan University of Finance and Economics \\ International Business School, Yunnan University of Finance and Economics \\ Kunming, Yunnan, P.R. China \\ yufejennyludan@126.com,20025859@qq.com,397169925@qq.com
}

\begin{abstract}
With sharply increasing of competition in labour market, many college students taken certificate tests at universities with the concept "the more certificates you have, the more opportunities you will gain in the future". Therefore, the more college students take part in certificate tests, the more attentions have been paid to the phenomenon of obtaining certificates. The thesis has investigated and analyzed the phenomenon, motivation and results about obtaining certificates among college students. As a result, it finds that there are many irrational attitudes and thoughts on this phenomenon. Thus, the governments, employers, colleges and the college students shall rationally consider the issue, and make scientific, rational, and correct guidances, which can help them to effectively arrange their lifes, studies and works, and then improve the effectiveness of talent cultivation.
\end{abstract}

Keywords-College students; Phenomenon of obtaining certificates; Motivation; Rational analysis

\section{INTRODUCTION}

Along with the fast development of social economy, employers have improved their requirements of the comprehensive quality for college students year by year, and the employment pressure in society has also become increasingly fierce. With the increase of college students enrollment numbers, the current number of graduates has been increased annually, so the severe employment pressure has forced the college students to adopt various measures to improve their self-values and enhance their own employment competitiveness. In all sectors of society, certificate is regarded as a ruler to measure one's capacity and such situation will certainly promote the upsurge among college students in obtaining certificates. Therefore, the group of people obtaining certificates in colleges has fast expanded. As for obtaining certificates, part of students have clear objectives while most students merely follow suit blindly. During colleges, when college students are lost, they will choose to obtain certificates to "fulfill" their college life, so as to obtain some spirit consolations. It is hoped that, through this research, all sectors of society can scientifically guide college students to correctly treat the phenomenon of obtaining certificates, guide college students to realize the importance of the combination between theory and practice so that thay can more scientifically and reasonably plan for the college life and career development path.

\section{Current Status ABout THE CERTIFICATE TEST AMONG COLLEGE STUDENTS}

\section{A. Diversity of Certificate Test Preparation among College Students}

As can be found from the investigation of the paper, the mode for college students to obtain certificates is diversified; $57 \%$ of students express that, after confirming the target certificate, they will collect corresponding data, actively consult others, and study autonomously; $60 \%$ of students express that, they will try their best to study the corresponding courses in school, so as to cope with the certificate tests; $44 \%$ of students will select to participate in corresponding training class after selecting the target type of certificate, for the training class can provide them with the relevant data and professional guidance, so that the pass rate of test can be improved; besides, there are also $40 \%$ of students who will choose online study through the internet, and this is more simplified, time-saving and energy-saving; of course, there are also students who simultaneously select several modes to study for the test; moreover, partial students will also cram for a test and adopt test-oriented mode for concentrated review.

\section{B. Arrangement of College Students for the Certificate Test Time}

College students are varied in the certificate test time, and partial "test madmen" almost spend all their time on campus taking certificate tests, and neglect the practice. According to the investigation of the paper, $8.82 \%$ of students spend above $80 \%$ of time taking certificate tests, $52.94 \%$ of students spend $50 \%-80 \%$ of time, $31.37 \%$ of students spend $30 \%-50 \%$ of time, and $6.86 \%$ of students spend $30 \%$ below of time in taking certificate tests. Therefore, it can be seen that, students spending above a half of time taking certificate tests can occupy above $60 \%$, which can reflect that certificate test has become a trend, while for these students who spend most of their time and energy taking certificate test, they cannot well distribute professional learning, certificate test and social practice time, or well handle the relationship among professional study, practice and certificate test. 


\section{Type of Certificate That Can Be Obtained By College Students}

Over the years, the type of certificates obtained by college students has become diversified, and there are above hundreds of them, which can be mainly classified into three types as follows: the first one is general certificate, such as Mandarin Certificate, CET- 4 certificate, CET- 6 certificate, and computer grade certificate; these certificates have basically become the certificates that must be equipped for each college student. The second one is ability-oriented certificate, such as TOEIC, IELTS, TOEFL and other performance certificates; these certificates are generally applied in certain field. The third one is professional certificate, such as human resources professional, marketing operator, E-commerce engineer, logistician, and teaching qualification certificate; these certificates have the most varieties, and cover a very wide range. Along with the mode of certificate test becoming serious, various certificates start to occur successively, and the idea of "more certificates mean more options" has led the thought of most students, so certificate test has become the struggling objective for them in colleges.

\section{Low Scientific Degree for Certificate Test Guidance}

The final objective for the certificate test guidance provided by various colleges for students is to improve the employment competitiveness of students, and the employment rate of the school. The guidance contents are mainly focused on government policy, the seizing of time in the test, the test skills, and the introduction of certificate test training institutions. Such guidance mode can be way too indistinct and one-sided, and students cannot correctly realize and understand the certificate test, which has caused the students failing to reasonably arrange the time for study, life and work. Even if the students have obtained the relevant certificates after consuming their time and energy, they cannot apply them in practice, so the practical value is largely decreased.

\section{AnAlysis ON THE CERTIFICATE TEST Motivation OF COLLEGE STUDENTS}

\section{A. External Factors}

\section{1) Employment Pressure}

The number of college graduates has been increased year by year along with the increase in the unemployed number and the sharp increase in employment pressure. During the period, the state's economy has entered into the new normal, and the economic system has also faced with major adjustment; the descending industrial situation, the shrinkage of employment demand, etc. have intensified the employment pressure [1]. The issue of difficult employment has made lots of students generate the crisis awareness of "graduation equals to unemployment", during which certificate test has naturally become the life-saving straw for most students. According to the investigation of the paper, students who have decided to take certificate test but haven't executed it can occupy $29.41 \%$, students who have taken a part of tests and prepared to continuously take other tests can occupy $56.86 \%$, students who haven't decided whether to take certificate test can occupy $5.88 \%$, and students who decide not to take certificate test can occupy $2.94 \%$, which can fully show the pursuit of students for various certificates.

\section{2) Degree Requirement}

At present, there are still a few colleges linking up the issuance of degree certificate with partial grading certificates. For instance, partial colleges have clearly stipulated in the bachelor degree awarding rules that, the school will not award the issuance of graduation certificate and the degree certificate without CET-4 certificate [2]. If students want to successfully graduate, they must obtain the relevant certificates.

\section{3) Industrial Access Regulations}

Jobs with higher requirement for technical and service quality, wide coverage and big mobility have implemented the employment access system, and in order to get such jobs, it is requested to pass the relevant training, and the students can only take the posts after passing the unified examination of the state, and obtaining the professional certificate. For instance, if you want to work in accounting industry, you must have the certificate of accounting profession, and in order to become a teacher, you must have the qualification to be a teacher, and obtain the corresponding industrial access certificate- teacher qualification certificate.

\section{4) Advertising Effect}

According to the investigation result of the paper, $50 \%$ of information about the certificate test of students is from the advertisement of training institutions. The advertisement of training institutions occupies each corner of college campus, making partial college students generate the sense of urgency for certificate test, and such information has deepened the wrong thought of college students about "certificate is the trick for winning in the employment process", and this has made them irrationally participate in training and certificate test.

\section{5) Dilemma of College Education}

The majors in colleges are dazzling, but many professional cultivation schemes and course setup are separated from the social demand, and cannot meet the demand of employment market [3]. Such education dilemma has made the employers prefer to use special certificate to evaluate, and check the capacity of students, and select talents as per the quantity of certificates. Such status has promoted the irrational certificate test of students.

\section{INTERNAL FACTORS}

\section{A. Blindly Follow}

Conformity is a typical psychological characteristic of college students [4]. Many students will take various certificate tests in swarms after seeing students around them taking certificate test, and won't consider whether it is suitable for them, or whether it is the certificate requested thereby; they even have no idea about whether these certificates are valuable to them; what they do is to take the same certificate test with others. It can be seen that, the certificate test taken under such conformity physiology has showed more blindness of college students as well as their aimless restlessness and anxiety. 


\section{B. Prove Individual Strength}

The various certificate tests can only be passed with endeavors and hard work. Thus, the obtaining of various certificates has become a mode to prove individual strength, and also an important approach to reinforce confidence and competitiveness. The quantity of certificates has gradually become the standard for the mutual affirmation of college students. Therefore, it has become a primary approach to gain self-identification and others' recognition through obtaining lots of certificates.

\section{The Generation of Supreme Pragmatism}

The generation after $95 \mathrm{~s}$ and advocating supreme pragmatism pays more attention to the knowledge that can bring employment opportunities to them and can exert actual effect on the improvement of personal capacity [5]. From this perspective, it can also be said as a rational choice to join in the force of certificate test. When being compared with the boring knowledge in campus classrooms, students prefer to accept the certificate test training in training institutions; for them, they will have one more option in the future after obtaining one certificate.

\section{Lack of Career Planning}

The Ministry of Education requests colleges to set career planning courses, but the effect isn't quite ideal [6]. College students still don't understand themselves, or the career and professional environment. Besides, traditional education has caused the lack of active exploration spirit among students, so they will undoubtedly feel at a loss or confused about their own career planning, and have no choice but to join in the force of certificate test, and seek psychological comfort.

\section{AnAlysis on the CeRtificAte Test Result of COLLEGE STUDENTS}

\section{A. Certificate and Employment Capacity}

1) Relation between the Quantity of Certificate and the Employment Capacity

The investigation result has showed that, the quantity of certificates has no obvious relation with the employment capacity of college students. Many students think that certificate test doesn't certainly improve their employment capacity in the future. The holding of various certificates can only indicate that they have passed the corresponding certificate tests, rather than possessing the capacity matched with the certificate. Although partial employers pay more attention to whether the employees have certain type of certificate, and this has become one method for the employers to judge the capacity of college students, but the certificate cannot fully reflect the capacity of employees, and relatively speaking, they pay more attention to the actual capacity, practical experience and comprehensive quality of employees, etc.

2) Relation between Certificate Type and Employment Capacity

The investigation result has showed that, the type of certificate and the employment capacity have certain correlation. Partial college students will choose office skill certificate, and generally, these certificates are the mark with basic working capacity. Secondly, professional qualification types of certificates are also very popular, and it represents the capacity for being engaged in certain career, and this direction is also generally the intentional working direction for students taking such certificate tests, and such certificates can indicate the professional capacity; meanwhile, it can also be regarded as the access certificate for certain industry. Furthermore, in industries with relatively stronger comprehensiveness, college students who want to be engaged in such industry in the future will take certificate tests, with higher authority and bigger gold content, which can represent a kind of special skill.

\section{B. Certificate Quality and Talent Cultivation}

\section{1) Inundant Certificate and Low Quality}

There are diversified certificates oriented to college students, some of them have higher gold content, but there are also some certificates with relatively low or rarely no gold content. For most students, they choose to get certificates after passing simple training. Such certificates are merely obtained through short-time cram, and short memory, so students won't systematically study and implement application. The certificates obtained through such approach can obtain shorttime interests, but they are not good for the long-term development of talents; meanwhile, this cannot create highlevel talents.

\section{2) Talent Disorder and Knowledge Devaluation}

College students have constantly participated in the group of certificate test, and this has caused decreased certificate quality, and meanwhile, brought "talent disorder" and "excessive consumption of talent educational background" as well as other issues, i.e., in the talent using process of various employers, posts are not matched with the educational background, majors and capacities of talents, and this has caused talent idling, the waste or misuse of excellent talents, mismatching, knowledge devaluation and other phenomena. Since college students blindly take all kinds of certificate tests, the employment rate matching the major has become quite low, and the disordered employment rate has also been gradually increased. A big batch of graduates cannot find posts matching their own majors, so they have no choice but to wait for employment or be employed disorderly. This is obviously a waste of talent resources, and a huge devaluation of professional knowledge, and can reflect that there are major issues in the employment quality of college graduates. 


\section{REFLECTIONS ON COUNTERMEASURES FOR THE RATIONAL CERTIFICATE TEST OF COLLEGE STUDENTS}

\section{A. About the Government}

The government shall conduct well the guidance and normalization of certificate test market. Firstly, the government shall conduct suitable and rightful macroeconomic regulatory, and create a relatively abundant job selection environment, alleviate the tense employment trend, normalize the certificate training market, and provide an excellent training environment for certificate test. Secondly, the force of certificate test in colleges has become increasingly powerful and prosperous, the type of certificates as well as the various training institutions have also been gradually increased. In order to alleviate the pressure brought to certificate test in all aspects, the government shall formulate corresponding regulations considering the relation between certificate and the relevant jobs, normalize the relation between certificate and jobs in policies and meanwhile, implement scientific guidance, so as to prevent the college students from taking certificate test blindly, and avoid the waste of finance, time and resources. Finally, in light of the chaotic certificate test market, partial training institutions are exaggerated in publicity, deceive and even cheat college students into participating in the training for certificate test; in light of such phenomenon, the government shall formulate pointed regulation methods accordingly. Meanwhile, the government shall also reinforce the supervision on the license-issuing authority and the relevant training institutions, ensure the objective fairness and transparency of the test process as well as the certificate quality, and prevent the occurrence of false certificate fabrication, etc.

\section{B. About the Employers}

The recruitment unit shall not pay too much attention on the certificate, and when college students correct their own attitude towards certificate test, the recruitment unit shall also make corresponding changes, and correct their attitude towards the recruitment of talents. The recruitment unit shall emphasize on the professional knowledge and professional skills of job seekers, consider the comprehensive quality of applicant, well and clearly handle the relationship between capacity and certificate, and correctly realize that certificate can hardly reflect the comprehensive capacity of applicants; besides, the recruitment units can connect their recruitment information with the information platform of schools, actively go into the campus, and reinforce the contact with the campus, so that the employers can know more about the comprehensive quality and capacity of students, which can not only alleviate the phenomenon of blindly pursuing for certificates among college students, but also make it possible to select talents that can match with the employment post.

\section{About the Colleges \\ 1) Correctly Treat Certificate Test and Professional Learning}

Schools shall guide students to reasonably allocate the time and energy between certificate test and professional learning. The main task for college students is the professional learning, and the professional knowledge can only be converted to practical skill through learning well professional knowledge, building professional foundation, and mastering professional theoretical knowledge. Thus, schools shall reinforce the perfection of professional course setup, frequently pay attention to the market demand for talents, frequently adjust professional courses as per the market, and make the professional courses targeted, flexible and practical. Meanwhile, schools shall perfect the setup of professional courses, cultivate talents with professional knowledge and practical skills, and assist the students to improve employment competitiveness fundamentally, increase the opportunities for college students to obtain the post, and let students get rid of the behavior of merely taking certificate tests to improve their competitiveness and increase employment opportunities. Certificate test shall be regarded as a mode of improving self-capacity, and a supplementation beyond professional knowledge learning; students simultaneously possessing professional knowledge and certificate can be recognized by the recruitment units. Therefore, it is requested to guide students to understand the dialectical relation between certificate test and professional knowledge; it is prohibited from attending to trifles, neglecting the essentials, and reserving the order of importance.

\section{2) Reorganize the On-campus Training Market}

At present, various kinds of guidance personnel and training institutions have filled every corner of schools, good or bad, so students can be tricked sometimes. Thus, schools shall reorganize the relevant issues about certificate test among students, and meanwhile, allocate it to appropriate department for management, and truly convert disorderliness into orderliness. Besides, specified department shall take charge and introduce some types of certificates that enjoy higher population among college students; meanwhile, the entire application training process shall be restricted by the system, so as to build a good on-campus training atmosphere.

\section{3) Scientifically and Reasonably Select Certification} Test Project

The certificates in the market are diversified, with different certificate issuance institutions, making students feel at a loss; as for the social recognition degree of these certificates, there can be doubts about the background of various certificates, and this requests the schools to conduct well the relevant control. When schools introduce various types of certificate, it is requested to pointedly introduce the relevant types of certificate recognized by the state, the professional post qualification certificates implementing vocational access restriction and the type of certificate that have obtained the certification of corresponding social institutions, and can help college students improve competitiveness in job market, and obtain the favor of recruitment unit, correctly guide students, encourage them to 
focus on the major and major related certificates, rather than blindly taking too many tests, and purely pursuing for the quantity.

\section{4) Fully Exert the Advantages of Colleges}

Fully utilize campus resources, and actively establish test points and certificate test tutoring institutions on campus; this can largely decrease the cost of financial resources and material resources in the certificate test process of students, and also scientifically set the time of training course, provide convenience for students to participate in the training, and also avoid the conflicts of training courses and professional courses for students. Fully apply teacher resources of schools, the school practice base and the resources of other aspects, select some teachers who are familiar with the contents of certificate test to enter into the application process for certificate test of students, and help students obtain the corresponding improvement of comprehensive capacity when obtaining certificate. Since the various recruitment units at present pay more attention to the practical action capacity of college students, when being compared with theories, during the certificate test learning process, each branched department established by schools shall build the awareness of emphasizing on practical capacity, and meanwhile, adopt correspondingly valid measures.

\section{ABOUT THE STUDENTS}

\section{A. Rationally Treat Certificate Test}

College students shall correctly understand the certificate, and shall not blindly follow the trend; it is requested to fully consider the personal demand conditions before making the decision on taking certificate test, and selecting which kind of certificate. It is requested to know that certificate is merely the stepping stone for job application, and cannot be absolutely depended, and they shall also know that most certificates, even if they are certificates with high gold content, will be merely regarded as a reference for interviewers, and are not the direct factor deciding the success or failure of the interview. As students, it is requested to frequently bear in mind that the most powerful certificate for us must be the graduation certificate and the degree certificate, so the main energy shall be focused on professional knowledge learning; it is requested to adhere to taking the professional knowledge as the main assignment, regard certificate test as supplemented course, and prevent order reversion.

\section{B. Reasonably plan for the certificate test time}

As college students, it is requested to complete career planning as soon as possible, make correct certificate test time arrangement and suitable certificate test plan, pointedly take certificate tests similar or suitable for career planning. Meanwhile, the selection of certificate test shall take the selfdemand as the references, and shall not blindly follow the trend, to prevent the energy and material of all aspects from being destroyed, and reasonably make an overall plan of the study life at college campus.

\section{Selection of Certificate}

The types of certificates are diversified, and after obtaining some general types of certificates, it is applicable to appropriately take some vocational restricted certificate tests as per the professional direction. In case of being dissatisfied about the learned major, it is applicable to take some certificates requested for personal life plan, and while obtaining the certificate, it is also requested to master the skills. The current social market requests more talents possessing solid professional knowledge and mastering solid technologies, so certificate test shall be refined, rather than excessive. Except this, certificate tests shall also combine personal interests and hobbies, personality characteristics, etc., and it is better to take the certificate tests that can be useful for the personal intentional industry in the future. The level of personal comprehensive quality cannot be measured with the quantity of certificates, and more luminous points of certificate can be reflected through combing personal hobbies and majors.

\section{CONCLUSION}

Along with the social development, the function that certificate can objectively reflect the capacity of the owner has been gradually degraded. Those certificates that used to prove the capacity level of one person have currently become papers that can merely impress interviewers, which has caused the unbalance among entire market. Therefore, it can be seen that, the key for improving self-competitiveness is to master stong professional knowledge and skills. As for obtaining certificates, first college students shall have a correct and rational cognition. The objective of obtaining certificates is not merely for obtaining a paper certificate and instead, it is to acquire more knowledge, promote professional learning and compensate for the insufficiencies in professional learning. The obtaining certificates and professional learning shall supplement each other, and it is absolutely wrong to blindly take certificate test and neglect the study of professional courses; it is important to recognize which one is more important to get more certificates or learn true knowledge. While college students have completed their career planning and corrected their attitudes towards certificate test, the government, colleges and all sectors of society shall also formulate corresponding guidance strategies to make college students rationally treat certificate test so that it can play its real role.

\section{ACKNOWLEDGEMENT}

This research was financially supported by the scientific research funds of Yunnan Province Department of Education "research on the effective path of undergraduate social practice from the perspective of service learning" (2017ZZX005). 


\section{REFERENCES}

[1] Tao Shuting. Analysis on the Hot Phenomenon of Certificate Test among On-campus College Students Majoring in Economics [J].The Guide of Science \& Education (Middle Ten-day Journal), 2017, (2): 177-178.

[2] Liu Yuliang, Wang Jing, Meng Chenchen, Yang Fangdi, and Jin Shengjie .Current Situation Research and Discussion about the Certificate Test of College Students in Shanghai City —-Taking Pudong New District as an Example [J]. Market Forum, 2016, (10): 76-86.

[3] Sun Sukui. Analysis and Countermeasures Reflections on the Reasons for On-campus College Students to Take Certificate Tests [J].Research and Review on Education, 2013 (5): 66-69.

[4] Pan Yunhua, and Liu Huan. Investigation and Research on the Current Status of Certificate Test among College Students[J]. Educational Review, 2012 (2): 81-83.

[5] Sun Wujun. Analysis on the Development Trend and Motivation of "Certificate Test" Behavior among College Students [J]. Imparting Knowledge and Educating People, 2008 (12): 56-57.

[6] Wen Jianhua. Rational Reflection on the "Certificate Craze" of College Students [J]. Education and Career, 2007 (15): 170-171. 